\title{
LEYES ELECTORALES, SISTEMAS DE PARTIDOS Y ELITES: EL CASO ESPAÑOL
}

RESUMEN. En este estudio se analiza la influencia de las leyes electorales en los sistemas de partidos, utilizando datos agregados, de encuesta y de entrevistas en profundidad, recogidos en España en las dos últimas décadas. El «efecto mecánico» de la ley electoral española ha resultado ser tan fuerte como el de muchos sistemas de distrito uninominal. Presentamos pruebas de una amplia difusión del voto «sofisticado» o «estratégico». Pero el "efecto no inmediato" de la ley electoral en el sistema de partidos tiene un carácter complejo y polifacético, no directo y determinista. Se demuestra que las percepciones, cálculos, estrategias y comportamiento de las élites de los partidos desempeñan un papel crucial de mediación entrc la ley electoral y la configuración global del sistema de partidos. Argumentamos que las leyes electorales tendrían un impacto directo y determinista en los sistemas de partidos sólo en el caso de que las élites conocieran a fondo los incentivos inherentes a la ley electoral, así como los niveles y distribución geográfica de sus propias bases de apoyo en el electorado y los de sus futuros socios de coalición o de fusión, y sólo si su objetivo prioritario a corto plazo fuera maximizar la representación parlamentaria de su partido, por encima de otros objetivos políticos.

El impacto de las leyes electorales en la estructura de los sistemas de partidos ha sido objeto de especulación y estudios eruditos durante un siglo, siendo, además, un tema recurrente en las investigaciones de ciencia política desde la publicación de Partidos Políticos, de Duverger, en 1951. Los efectos «mecánicos» o «inmediatos» de los sistemas electorales (Duverger, 1954, 226; y Rae, 1971, 67) han quedado demostrados de forma sistemática y convincente: las leyes electorales varían significativa y previsiblemente en el 
modo en que distribuyen escaños en los organismos legislativos de acuerdo con la participación del voto popular correspondiente a cada partido. El efecto «sicológico» postulado por Duverger $(1954,226$; véase también Downs, $1957,48)$ también se ha confirmado empíricamente en gran medida, aunque no de una manera uniforme. Varios estudios (Spafford, 1972; Fisher, 1973; Cain, 1978; y Bensel y Sanders, 1979) han demostrado la existencia del «voto sofisticado» o «estratégico».

Hasta ahora, sin embargo, no se han examinado con mucha precisión los "efectos no inmediatos» de las leyes electorales en la estructura de los sistemas de partidos (Rae, 1971, 68). Las investigaciones de este impacto a largo plazo han consistido por lo general en inferencias especulativas: las correlaciones entre los sistemas de representación proporcional y el multipartidismo, por un lado, y entre las leyes electorales mayoritarias y los sistemas bipartidistas, por otro, se consideran simplemente reflejos de este efecto no inmediato o a largo plazo. Sin embargo, un número significativo de destacadas excepciones a estas tendencias generales (Canadá y Austria, por ejemplo) han impulsado un debate sobre si es o no adecuado establecer nexos causales en esta relación. A Riker (1986), por ejemplo, le pareció importante distinguir si las proposiciones de Duverger deben considerarse «hipótesís» o «leyes», y si son «probabilísticas» o «deterministas». Sartori (1986) entró a debatir estas objeciones y añadió otras de su cosecha, referentes a si la influencia de las leyes electorales en los sistemas de partidos debe describirse en términos de «efectos» o «efectos secundarios», y a si éstas «producen» o simplemente «mantienen» ciertos tipos de sistemas de partidos.

Dada la compleja naturaleza de los fenómenos investigados y la imperfecta asociación empírica entre las leyes electorales y los sistemas de partidos, dudo que nuestra comprensión de estos efectos no inmediatos pueda avanzar mucho más mediante un debate de características tan abstractas. En este sentido, estoy más de acuerdo con Rose, quien argumentó que un avance significativo en esta línea sólo puede lograrse ampliando el campo de análisis: «Para comprender el funcionamiento de los sistemas electorales en la práctica hay que tener en consideración tanto las propiedades genéricas del sistema como los contextos nacionales específicos... El funcionamiento de un sístema electoral no puede entenderse simplemente en términos de propiedades definitorias y abstractas; tiene que evaluarse mediante el anásis de un sistema electoral en un sistema político» $(1984,78)$. Esta sugerencia es coherente con una afirmación anterior de Rae, quien recomendó prudencia a la hora de hacer inferencias sobre los efectos a largo plazo de las leyes electorales en los sistemas de partidos, «puesto que las asociaciones observadas pueden reflejar la influencia de terceros factores o factores subyacentes al sistema político, que son independientes de la ley electoral» (1971, 68). 
Este artículo representa un intento de explorar un conjunto crucial de factores mediadores de este tipo: las percepciones, cálculos, estrategias y comportamiento de las élites partidistas, en interacción con la estructura de incentivos creada por la propia ley electoral. Comienza con un examen de los efectos mecánicos y sicológicos de la ley electoral española en la distribución partidista de escaños. Esta parte del análisis está basada en datos agregados relativos a España, de los años setenta y ochenta, así como en dos encuestas postelectorales grandes, realizadas en 1979 y $1982^{\prime}$. Un aspecto de este análisis utiliza simulaciones (diseñadas y realizadas por Giacomo Sani) de diferentes combinaciones de partidos, que sirven de base para especular sobre los resultados más probables de las diferentes posibilidades de coalición, fusión o escisión ${ }^{2}$. El eje central del estudio -la investigación de las razones por las que las élites pueden tener un comportamiento inconsecuente con las estructuras de incentivos inherentes a la ley electoral- se basa en extensas entrevistas en profundidad a líderes políticos españoles en diversas fases de la transición y de la consolidación del régimen democrático actual ${ }^{3}$.

España nos ofrece una oportunidad excelente para medir el gran impacto de una ley electoral en un nuevo y cambiante sistema de partidos. La ley electoral adoptada en 1977 es una forma de representación proporcional sustancialmente restringida, cuya «fuerza», o desviación de una proporcionalidad pura en la asignación de escaños parlamentarios, es comparable a los sistemas de distrito uninominales. Como demostraremos más adelante, existen suficientes pruebas de la existencia de efectos mecánicos y sicológicos de este mecanismo electoral. Dada la introducción de un sistema electoral vigoroso en un sistema de partidos nuevo y extremadamente fragmentado, la ley electoral, como cabría esperar, ejerció una influencia considerable en las primeras elecciones democráticas, contribuyendo a simplificar la estructura de la competencia partidista. Esta ley sobrerrepresentó a los dos partidos nacionales más grandes e infrarrepresentó sustancialmente a los pequeños

' Las dos encuestas $(\mathrm{N}=5.439$ y 5.463$)$ estuvieron dirigidas por Giacomo Sani, Goldie Shabad y este autor, y se financiaron parcial o completimente con ayudas de la National Science Foundation, núms. SOC $77-16451$ y SES-8309162. (Las opiniones, conclusiones y resultados expresados en este artículo, sin embargo, pertenecen al autor y no reflejan necesariamente los de aquella institución.) La encuesta de 1982 se realizó (en colaboración con Juan Linz, José Ramón Montero y Hans-Jürgen Puhle) con la generosa colaboración de Stiftung Volkswagenwerk, de Alemania Occidental.

${ }^{2}$ En una versión preliminar de este artículo había participado Giacomo Sani como coautor (Sani y Gunther, 1986). Agradezco a Sani su autorización para el uso de esas simulaciones en este estudio sustancialmente revisado.

${ }^{3}$ Se llevaron a cabo aproximadamente 200 entrevistas en profundidad extensas (de una duración habitual de más de una hora) con los líderes de los partidos en 1978, 1979, 1981, 1983, 1984 y 1986. Los entrevistados incluyeron dirigentes de los cinco partidos nacionales (PSOE, UCD, PCE, AP y CDS) y de los partidos regionales más importantes (los catalanes CDC y ERC y los vascos PNV y EE). También se incluyó un total de once horas de entrevistas con tres Presidentes del Gobierno español en la democracia. 
partidos con bases de apoyo geográficamente dispersas, negándoles, en su inmensa mayoría, la representación parlamentaria. Este factor, combinado con las leyes de financiación de los partidos (que reforzaban los sesgos inherentes a la ley electoral) ${ }^{4}$, condujo a muchos partidos a la extinción, inmediatamente después de las elecciones de 1977.

El sistema de dos partidos dominantes que tomó cuerpo en aquel momento (y que se reafirmó en las elecciones de 1979) parecía «tener sentido», puesto que constituía una derivación lógica de la ley electoral y de la distribución de las preferencias y los valores políticos del electorado en general (véase Gunther, Sani y Shabad, 1986). Pero el alineamiento de las fuerzas partidistas que surgió de las dos primeras elecciones no fue estable, a pesar de su compatibilidad con estos apoyos institucionales y socioestructurales. Así, pues, en 1982, los cambios operados en la distribución de escaños reestructuraron drásticamente el sistema de partidos y condujeron directamente a la extinción del partido centrista que había gobernado inicialmente en España. Los sesgos de representación inherentes a la ley electoral desempeñaron un papel importante en la obtención de este resultado, y han servido de obstáculo para el surgimiento de un nuevo partido centrista que sucediera al ahora extinguido Unión de Centro Democrático (UCD). De este modo, la ley electoral española ha continuado teniendo un poderoso impacto en la estructura de la competencia partidista.

El caso español tiene también un interés considerable por ilustrar el grado en que un sistema de partidos puede verse influido por las acciones independientes de las élites. A pesar de conocerse ampliamente la influencia de la ley electoral en las perspectivas de obtener representación parlamentaria, muchas de estas élites desarrollaron estrategias y comportamientos que, a la luz de la estructura de incentivos inherente a la ley electoral, pueden considerarse irracionales, cuando no suicidas. Resumiendo, este conjunto de factores «mediadores» ha afectado a la estructura de la competencia partidista de una forma que no podía haberse previsto, basándose exclusivamente en la lógica de la ley electoral.

Un análisis detallado del impacto de la ley electoral en el sistema de partidos español sugiere algunas modificaciones en nuestra comprensión convencional del impacto no inmediato de los sistemas electorales. Resumiéndolas, diríamos que estos efectos no inmediatos serían directos, uniformes y predecibles sólo si se mantuvieran estrictamente ciertos supuestos relativos

4 La ley de financiación de las campañas, promulgada en marzo de 1977, garantiza subvenciones públicas a los partidos según el número de escaños obtenidos en la elección precedente y por cada voto útil (es decir, votos a candidatos con éxito). Los partidos que no obtienen un solo diputado o senador no reciben nada. Resumiendo, los ricos se hacen más ricos, y los pobres acaban en la quiebra. De forma similar, la ley de diciembre de 1978, que sufraga los gastos anuales de funcionamiento de los partidos, resulta perjudicial para los partidos más pequeños: los fondos públicos están destinados a los grupos parlamentarios y por cada diputado y senador elegidos. 
a factores tales como las motivaciones primordiales de las élites de los partidos y, desde luego, los niveles de apoyo electoral de cada partido. La historia posterior a la muerte de Franco de los partidos de centro y derecha revela claranente que estas condiciones estuvieron ausentes en diversas coyunturas cruciales.

\section{LA LEY ELECTORAL ESPAÑOLA: SUS ORIGENES Y CONSECUENCIAS}

La ley electoral, promulgada por Real Decreto de 18 de marzo de 1977, fue el producto de un complejo entramado de deliberaciones que incluyó discusiones entre el Presidente, Adolfo Suárez, y representantes de diversas fuerzas de la oposición. Estas decisiones conllevaron renuncias y compromisos en una gran variedad de asuntos relativos a los partidos y a la sociedad en sentido más amplio. La decisión de optar por un sistema electoral antes de las primeras elecciones democráticas en España tuvo una significación particularmente importante desde el punto de vista de la legitimidad y viabilidad del nuevo régimen. Hubo de lograrse un difícil equilibrio entre la necesidad de crear un sistema de partidos conducente a un gobierno estable y la necesidad de representar los intereses de importantes grupos sociales y políticos. Por un lado, había que reducir la fragmentación excesiva del nuevo sistema de partidos para facilitar la formación de gobiernos con capacidad para promulgar leyes y llevar a cabo esos programas en períodos razonables de tiempo. Este fue un tema que preocupaba muy especialmente a principios de 1977 , cuando se fundaron más de cien partidos políticos ( 78 de los cuales presentaron candidatos y obtuvieron votos en las elecciones del 15 de junio). La experiencia de la Segunda República sugirió a muchos observadores informados que la excesiva fraccionalización parlamentaria perjudicaría las perspectivas de gobernabilidad ${ }^{5}$. Por otro lado, la exclusión de fuerzas políticas significativas de un parlamento constituyente podría amenazar la legitimidad del nuevo régimen: los grupos excluidos de las deliberaciones sobre el establecimiento de las instituciones básicas y los procedimientos de una nueva democracia pueden, simplemente por su exclusión, rechazar cualquier constitución que pudiera crearse. $\mathrm{Y}$, a la inversa, los

5 El sistema de «voto limitado» adoptado en 1931 facilitó la proliferación de partídos independientes y produjo un sistema de partidos muy fragmentado. Más de 20 partidos obtuvieron representación parlamentaria en cada una de las tres legislaturas de la Segunda República, teniendo once partidos, por lo menos, diez o más escaños en cada período. En ninguna de estas legislaturas controló un solo partido más del 23 por 100 de los escaños, Jo que impuso la necesidad de coaliciones multipartidistas de amplias bases para la formación de un gobierno. Como era de esperar, eso condujo a una considerable inestabilidad ninistcrial: durante los reinticinco meses de la legislatura de las Cortes de 1933-35, por ejemplo, se produjeron 13 crisis de gobierno (véase Gunther, Sani y Shabad, 17-19). 
grupos directamente implicados en el proceso constituyente están más predispuestos a interesarse por preservar el nuevo régimen que han ayudado a crear (véase Gunther, 1985).

Estas opciones también se complicaron por los cálculos basados en intereses partidistas. No es sorprendente descubrir que los grupos políticos favorecieron la adopción de diferentes sistemas electorales en función de sus estimaciones del tamaño y distribución geográfica de sus respectivos bloques de simpatizantes. De este modo, un partido cuyos líderes creían que iba a obtener mayorías simples en una gran parte del pais, como el partido de derecha, Alianza Popular (AP), favoreció la adopción de un sistema de distrito uninominal, esperando que este sistema convirtiera esa ventaja electoral en una mayor distancia o una mayoría de escaños en el parlamento. Inversamente, partidos más pequeños con bases de apoyo geográficamente dispersas, tales como el Partido Comunista de España (PCE), favorecieron fórmulas de representación proporcional. Y los partidos exclusivamente regionalistas, como los nacionalistas vascos y catalanes (PNV, CDC y ERC), estaban enormemente interesados en el trazado de los límites de los distritos electorales. La selección de un sistema electoral fue (y así se consideró en términos generales) crucial, en la medida en que afectaba directamente las perspectivas de los partidos de apostar por una posición dominante o, por lo menos, visible en el escenario político.

La ley electoral promulgada por el Gobierno de Suárez representó un compromiso entre las conflictivas exigencias de los diversos partidos. De acuerdo con las preferencias iniciales del Gobierno y los requerimientos de los comunistas y socialistas (tanto el PSOE como el PSP de Tierno), en la Ley de Reforma Política de 1976 y la ley electoral de 1977 se aprobaron los principios de representación proporcional. Sin embargo, para asegurar la aprobación por las Cortes de la Ley de Reforma (que no fue tarea fácil, puesto que a las últimas Cortes de Franco se les pedía cometer suicidio institucional y comenzar a desmantelar el antiguo régimen), el Presidente Suárez dependía de los votos de muchos procuradores afiliados al partido recientemente creado, Alianza Popular. Este hecho permitió que Suárez negociara con éxito la inclusión de "correctivos» en la ley electoral, diseñados para reducir la fragmentación del sistema de partidos e, indirectamente, para reducir la proporcionalidad de la representación en el futuro Congreso de los Diputados. De este modo, la Ley de Reforma estipulaba que el Congreso tendría 350 miembros; que se requeriría un número mínimo de votos para obtener representación parlamentaria; que los distritos electorales coincidirían normalmente con las 50 provincias; y que a cada provincia se le adjudicaría un número mínimo de representantes. La ley electoral de 1977 resolvió varios temas que habían quedado pendientes por la Ley de Reforma del año anterior, mediante la determinación, sobre todo, de utilizar el método D’Hont del «resto mayor» en la distribución de escaños y de que, en la práctica, las 
provincias más pequeñas recibirían una representación mínima de tres escaños.

\section{Los efectos mecánicos}

En este sistema electoral la representación está sesgada por dos motivos. El primero se deriva de los esfuerzos de la ley por lograr un «mayor equilibrio territorial en la representación» (Ministerio del Interior, 1979, 27), lo que se traduce en una sobrerrepresentación de las provincias pequeñas en el Congreso. Esto significó, por ejemplo, que, en 1977, la rural y poco poblada Soria enviara un diputado a las Cortes por cada 34.636 habitantes, mientras que el distrito de Madrid sólo recibía uno por cada 139.659.

La segunda causa de sesgo proviene del producto combinado de la existencia de muchos distritos pequeños con la utilización del sistema de D'Hont de asignación de escaños. Rae ha argumentado que «la fórmula D'Hont penalizará en sumo grado a los partidos pequeños, a menos que el distrito sea muy grande o que el sistema de partidos esté muy fraccionalizado», es decir, que «la fuerza competitiva esté... dividida entre muchos» partidos (Rae, 1971,33 y 53). Pero en otro estudio (Sani y Gunther, 1986) habíamos demostrado que sólo existe una fraccionalización considerable en una cuarta parte o un tercio de las provincias españolas, principalmente en las zonas donde los partidos regionales son fuertes; de aquí que este factor mitigante esté ausente en la mayoría de los distritos. El otro elemento compensatorio sólo es aplicable a unas pocas provincias, ya que, en su gran mayoría, los distritos son pequeños: siete provincias están representadas por tres diputados, ocho provincias por cuatro representantes, y 13 distritos envían solamente cinco diputados a las Cortes. Rae $(1971,116-7)$ sugiere que los sistemas PR serán razonablemente proporcionales en la distribución de escaños únicamente en aquellos distritos representados por siete o más diputados aproximadamente: sólo 19 de las 50 provincias españolas corresponden a esta categoría, y sólo seis distritos eligen diez o más miembros del Congreso español. Sesgos importantes de representación afectan a la distribución de escaños en los restantes distritos, y mientras más pequeño es el distrito, más se aproximan las distorsiones producidas a las inherentes a los sistemas de distrito uninominal. El impacto neto del sistema de D'Hont, el reducido tamaño de los distritos y la sobrerrepresentación de los distritos rurales poco poblados puede observarse mejor comparando dos provincias: Madrid, representada por 32 diputados, y Zamora, que elige a cuatro representantes. Como puede observarse en el cuadro 1, el gran tamaño del distrito de Madrid tiene como resultado que se aproxime razonablemente a una distribución proporcional de escaños, pero la infrarrepresentación del distrito globalmente considerado significa que el cociente entre votos obtenidos y diputados elegidos 
es extraordinariamente alto. A modo de contraste, la ventaja en votos de UCD en Zamora se convirtió (como resultado de ser un distrito pequeño) en una enorme mayoría representativa. Además, se necesitan muchos menos votos para elegir a un diputado que en Madrid.

\section{CUADRO 1}

Distribuciones de votos y escaños en dos distritos: 1979

\begin{tabular}{|c|c|c|c|c|c|}
\hline & Votos & $\begin{array}{l}9 \text { de de } \\
\text { votos }\end{array}$ & Escaños & $\begin{array}{l}\% \text { de } \\
\text { escaños }\end{array}$ & $\begin{array}{c}\text { Votos por } \\
\text { escaño }\end{array}$ \\
\hline \multicolumn{6}{|l|}{ Madrid } \\
\hline 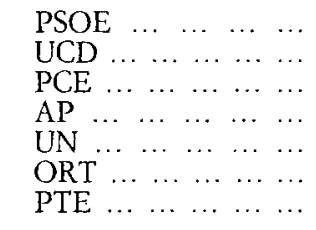 & $\begin{array}{r}769.328 \\
764.830 \\
310.496 \\
198.345 \\
110.730 \\
48.345 \\
25.832\end{array}$ & $\begin{array}{r}34,9 \\
34,7 \\
14,1 \\
9,0 \\
5,0 \\
2,2 \\
1,2\end{array}$ & $\begin{array}{r}12 \\
12 \\
4 \\
3 \\
1 \\
0 \\
0\end{array}$ & $\begin{array}{r}37,5 \\
37,5 \\
12,5 \\
9,4 \\
3,1 \\
0 \\
0\end{array}$ & $\begin{array}{r}64.111 \\
63.736 \\
77.624 \\
66.115 \\
110.730 \\
-\end{array}$ \\
\hline \multicolumn{6}{|l|}{ Zamora } \\
\hline $\begin{array}{llllll}\operatorname{UCD} & \ldots & \ldots & \ldots & \ldots & \ldots \\
\operatorname{PSOE} & \ldots & \ldots & \ldots & \ldots \\
\operatorname{AP} & \ldots & \ldots & \ldots & \ldots & \ldots \\
\operatorname{PCE} & \ldots & \ldots & \ldots & \ldots & \ldots\end{array}$ & $\begin{array}{r}61.025 \\
27.143 \\
19.603 \\
3.506\end{array}$ & $\begin{array}{r}51,0 \\
22,7 \\
16,4 \\
2,9\end{array}$ & $\begin{array}{l}3 \\
1 \\
0 \\
0\end{array}$ & $\begin{array}{c}75,0 \\
25,0 \\
0 \\
0\end{array}$ & $\begin{array}{l}20.342 \\
27.143 \\
- \\
-\end{array}$ \\
\hline
\end{tabular}

UCD: Unión de Centro Democrático (Centro-Centro Derecha; Adolfo Suárez).

PSOE: Partido Socialista Obrero Español (Socialista; Felipe González).

PCE: Partido Comunista de España (Eurocomunista; Santiago Carrillo).

AP: $\quad$ Alianza Popular (Conservador; Manuel Fraga).

UN: Unión Nacional (Extrema Derecha; Blas Piñar).

ORT: Organización Revolucionaria de Trabajadores (Extrema Izquierda).

PTE: Partido del Trabajo de España (Extrema Izquierda).

Estos sesgos de representación tuvieron una importancia política considerable en la configuración global del sistema de partidos, posibilitando que la UCD formara gobiernos minoritarios de un solo partido en 1977 y 1979, a pesar de haber recibido poco más de un tercio de los votos obtenidos en esas elecciones. Este impacto mecánico del sistema electoral puede apreciarse examinando los resultados electorales de 1979 en la región de Castilla-León, de la que forma parte la provincia de Zamora. El reducido tamaño medio de los distritos en esa región (cuatro de sus provincias eligieron sólo a tres diputados, tres eligieron a cuatro y las otras dos a cinco y seis representantes, respectivamente) convirtieron la mayoría simple de UCD en una enorme mayoría en términos de representación parlamentaria. La UCD recibió el 49,9 
por 100 de los votos obtenidos en toda la región, pero eligió el 70,5 por 100 de sus diputados a Cortes: 31 , o nueve más de los que le habrían correspondido si, en lugar de nueve distritos provinciales independientes, hubiera existido un único distrito grande para toda la región. La sobrerrepresentación de la UCD en regiones como Castilla-León creó una mayoría «fabricada» para este partido que, en combinación con el «voto constructivo de no confianza» de la Constitución, posibilitó que el partido gobernara solo de 1977 a 1982.

Incluso aunque los sesgos de representación observados en la provincia de Zamora queden en cierta forma compensados por la existencia de provincias grandes como Madrid y Barcelona (cuyos 32 y 33 escaños producen una distribución de escaños razonablemente proporcional), existen suficientes provincias como Zamora para que se produzca un fuerte efecto mecánico global. En general, los dos partidos más grandes están sobrerrepresentados en el Congreso de los Diputados; los partidos más pequeños con bases de apoyo geográficamente dispersas están infrarrepresentados (siendo más devastadora su infrarrepresentación a medida que el partido es más pequeño), mientras que los partidos con bases de apoyo concentradas geográficamente (como los nacionalistas vascos y catalanes) reciben una representación más o menos proporcional. Estos sesgos de representación pueden observarse en el cuadro 2, que presenta datos electorales de las cuatro elecciones democráticas en España hasta la fecha.

Lo que es más sorprendente es que estos sesgos de representación son más fuertes que los encontrados en cualquier sistema $\mathrm{PR}$ actualmente en uso en las sociedades industrializadas occidentales y que, efectivamente, son $\tan$ fuertes como los que se encuentran en sistemas de distrito uninominal. En el cuadro 3 se compara España con otras democracias occidentales, según sus puntuaciones en el Indice. de Proporcionalidad de Rose. Como puede observarse, el sistema electoral español es sorprendentemente no proporcional.

Estos datos también proporcionan algunas pruebas sobre el efecto no inmediato que se produce en el sistema de partidos español. El aumento ininterrumpido de la puntuación española de proporcionalidad en cada elección sucesiva es un reflejo del hecho de que el sistema electoral de partidos está adecuándose progresivamente al sistema parlamentario de partidos ${ }^{6}$. En 1977, por ejemplo, partidos a los que se había creído competidores viables

- Conviene observar que una puntuación alta en el Indice de Proporcionalidad no implica necesariamente que el sistema electoral sea «débil» (es decir, que ejerza poca influencia en la configuración del sistema de partidos). Esta medida del efecto mecánico de la ley electoral no tiene en consideración el efecto no inmediato de un sistema electoral, que puede ser tan potente como para desanimar completamente la entrada en el proceso de competidores potenciales en condiciones desfavorables. Los Estados Unidos, por ejemplo, obtienen una puntuación alta, debido, al menos en parte, a la falta de terceros partidos que desafíen el sistema bipartidista que la ley electoral estadounidense había ayudado a crear (Duverger, 1963, 218-220). 


\section{CUADRO 2}

Porcentajes de votos y escaños en el Congreso de los Diputados: 1977 a 1986

$\begin{array}{lllllll}\text { ELEC. } 1977 & \text { ELEC. } 1979 & & \text { ELEC. } 1982 & \text { ELEC. } 1986 \\ \begin{array}{l}\% \text { de } \% \text { de } \\ \text { votos escaños }\end{array} & \begin{array}{l}\% \text { de } \% \text { de } \\ \text { votos escaños }\end{array} & \begin{array}{l}\% \text { de } \% \text { de } \\ \text { votos escaños }\end{array} & \begin{array}{l}\% \text { de } \% \text { de } \\ \text { votos escaños }\end{array}\end{array}$

Partidos nacionales

\begin{tabular}{|c|c|c|c|c|c|c|c|c|}
\hline PSOE $\ldots \ldots \ldots \ldots$ & 28,9 & 33,7 & 30,5 & 34,6 & 48,4 & 57,7 & 44,4 & 52,6 \\
\hline $\begin{array}{llllll}U C D & \ldots & \ldots & \ldots & \ldots\end{array}$ & 34,0 & 47,1 & 35,1 & 48,0 & 6,9 & 3,1 & - & - \\
\hline $\begin{array}{llllll}\mathbf{A P} & \ldots & \ldots & \ldots & \ldots\end{array}$ & 8,0 & 4,6 & 6,1 & 2,6 & 26,4 & 30,6 & 26,1 & 30,0 \\
\hline $\begin{array}{llllll}\text { PCE } & \ldots & \ldots & \ldots & \ldots\end{array}$ & 9,2 & 5,7 & 10,8 & 6,6 & 3,9 & 1,1 & 4,7 & 2,0 \\
\hline $\operatorname{PSP} * \ldots \ldots \ldots$ & 4,4 & 1,7 & - & 一 & - & 一 & - & - \\
\hline $\begin{array}{llllll}\text { CDS } & \ldots & \ldots & \ldots & \ldots\end{array}$ & - & - & - & 一 & 2,9 & 0,6 & 9,2 & 5,4 \\
\hline Otros $\ldots \ldots \ldots$ & 6,5 & 0 & 6,4 & 0,3 & 2,5 & 0 & 3,7 & 0 \\
\hline
\end{tabular}

\section{Partidos regionales}

\begin{tabular}{|c|c|c|c|c|c|c|c|c|}
\hline $\mathrm{PDC} / \mathrm{CiU} \ldots \ldots$ & 2,8 & 3,1 & 2,7 & 2,3 & 3,7 & 3,4 & 5,1 & 5,1 \\
\hline $\begin{array}{llllll} & \ldots N V & \ldots & \ldots & \ldots & \ldots\end{array}$ & 1,7 & 2,3 & 1,7 & 2,0 & 1,9 & 2,3 & 1,5 & 1,7 \\
\hline $\begin{array}{llllll}\mathrm{EE} & \ldots & \ldots & \ldots & \ldots\end{array}$ & 0,3 & 0,3 & 0,4 & 0,3 & 0,5 & 0,3 & 0,5 & 0,6 \\
\hline HB $\ldots \ldots$ & - & 一 & 1,0 & 0,9 & 1,0 & 0,6 & 1,2 & 1,4 \\
\hline Otros $\ldots \ldots \ldots \ldots$ & 3,9 & 1,4 & 5,0 & 2,6 & 1,9 & 0,3 & 3,6 & 1,1 \\
\hline
\end{tabular}

PSP: $\quad$ Partido Socialista Popular (Enrique Tierno Galván; se unió al PSOE en 1978).

* Conviene señalar que tres de los seis escaños del PSP en las Cortes fueron resultado de coaliciones con partidos regionalistas.

CDS: Centro Democrático y Social (Adolfo Suárez; surgido de una escisión de UCD).

PDC/CiU: Pacte Democràtic per Catalunya (1977) y Convergència i Unió (coaliciones nacionalistas catalanas lideradas por Jordi Pujol y Convergencia Democrática de Cataluña).

EE: Euskadiko Ezquerra (coalición nacionalista vasca de izquierda; después partido).

HB: $\quad H e r r i$ Batasuna (grupo nacionalista vasco pro-ETA, de extrema izquierda).

Otros que obtuvieron escaños en el Congreso: Nacionales: Unión Nacional. Regionales: Esquerra Republicana de Catalunya, Partido Socialista de Andalucía, Unió del Centre i la Democracia Cristiana de Catalunya, Candidatura Aragonesa Independiente de Centro, Candidatura Independiente de Centro (Castellón), Unión del Pueblo Navarro, Partido Aragonés Regionalista, Unión del Pueblo Canario, Coalición Galega, Unió Valenciana y Agrupaciones Independientes Canarias. 


\section{CUADRO 3}

\section{La proporcionalidad de los sistemas electorales}

\section{Indice de proporcionalidad *}

\section{Sistemas $P R$}

Austria $\ldots \ldots \ldots \ldots \ldots \ldots \ldots$

\begin{tabular}{l}
99 \\
98 \\
97 \\
97 \\
97 \\
96 \\
96 \\
96 \\
95 \\
95 \\
94 \\
94 \\
93 \\
91 \\
90 \\
88 \\
87 \\
86 \\
83 \\
81 \\
\hline
\end{tabular}

$\begin{array}{lllllllllll}\text { Alemania } & \ldots & \ldots & \ldots & \ldots & \ldots & \ldots & \ldots & \ldots & \ldots & \ldots\end{array}$

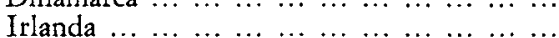

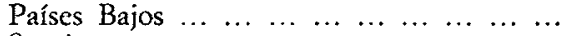

$\begin{array}{lllllllllllll}\text { Suecia } & \ldots & \ldots & \ldots & \ldots & \ldots & \ldots & \ldots & \ldots & \ldots & \ldots & \ldots\end{array}$

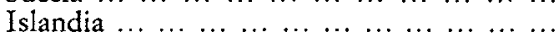

$\begin{array}{llllllllllll}\text { Suiza } & \ldots & \ldots & \ldots & \ldots & \ldots & \ldots & \ldots & \ldots & \ldots & \ldots & \ldots\end{array}$

$\begin{array}{llllllllllll}\text { Finlandia } & \ldots & \ldots & \ldots & \ldots & \ldots & \ldots & \ldots & \ldots & \ldots & \ldots\end{array}$

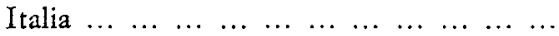

$\begin{array}{lllllllllllll}\text { Israel } & \ldots & \ldots & \ldots & \ldots & \ldots & \ldots & \ldots & \ldots & \ldots & \ldots & \ldots\end{array}$

$\begin{array}{lllllllllll}\text { Bélgica } & \ldots & \ldots & \ldots & \ldots & \ldots & \ldots & \ldots & \ldots & \ldots & \ldots \\ \end{array}$

$\begin{array}{lllllllllll}\text { Portugal } & \ldots & \ldots & \ldots & \ldots & \ldots & \ldots & \ldots & \ldots & \ldots & \ldots\end{array}$

$\begin{array}{llllllllllll}\text { Noruega } & \ldots & \ldots & \ldots & \ldots & \ldots & \ldots & \ldots & \ldots & \ldots & \ldots\end{array}$

$\begin{array}{llllllllllll}\text { Luxemburgo } & \ldots & \ldots & \ldots & \ldots & \ldots & \ldots & \ldots & \ldots & \ldots\end{array}$

$\begin{array}{llllllllllll}\text { Grecia } & \ldots & \ldots & \ldots & \ldots & \ldots & \ldots & \ldots & \ldots & \ldots & \ldots & \ldots\end{array}$

España (elecciones 1986) $\ldots \ldots \ldots \ldots$...

España (elecciones 1982) ... $\ldots \ldots \ldots \ldots$

España (elecciones 1979) ... $\ldots . . . . . . . .$.

España (elecciones 1977) $\ldots . \ldots \ldots \ldots$

Promedio (excluyendo España)

Sistemas no $P R$

Estados Unidos (House, 1980) ... ... ... ...

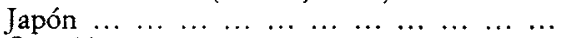

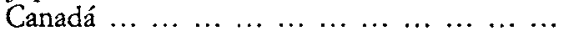

$\begin{array}{lllllllllll}\text { Australia } & \ldots & \ldots & \ldots & \ldots & \ldots & \ldots & \ldots & \ldots & \ldots & \ldots\end{array}$

Gran Bretaña $\ldots \ldots \ldots \ldots \ldots \ldots \ldots$

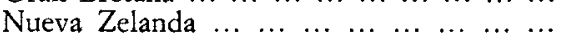

Francia

$\begin{array}{r}94 \\ 91 \\ 88 \\ 87 \\ 85 \\ 80 \\ 79 \\ \hline 86\end{array}$

Promedio

* El índice es la suma de los valores absolutos de las diferencias entre el número de escaños correspondiente a cada partido y su núcero de votos. Esta suma se divide por dos y se sustrae de 100 .

Fuente (excepto para España): Rose, 1984, 75. 
para posiciones de responsabilidad gubernamental —como el Partido Socialista Popular (PSP) de Tierno Galván y el Equipo Demócrata Cristiano-- estuvieron infrarrepresentados drásticamente o se les negó abiertamente una representación parlamentaria, viéndose forzados a la quiebra y obligados a dejar de existir. Pero la continuación de puntuaciones bajas en España también sugiere que ha habido un «retraso» considerable en este proceso: que algunos partidos están poco dispuestos a ajustarse a los dictados de la ley electoral. Este resultado, así como el comportamiento claramente «irracional» exhibido en 1982 por los líderes importantes de los partidos, los examinaremos algo más detalladamente en las conclusiones de este trabajo.

\section{Voto sofisticado}

Aparte de los efectos mecánicos observados anteriormente, la ley electoral española ha dado origen a una cantidad considerable de votos «sofisticados» o «estratégicos», lo que indica que la hipótesis de Duverger sobre el efecto sicológico funciona bastante intensamente. Algunas investigaciones anteriores (p. ej., Grumm, 1958; y Shively, 1970) encontraron pocos indicios que apoyaran la afirmación de este autor de que, bajo ciertos tipos de ley electoral, los votantes preferirán dar su voto a partidos que no constituyen su primera opción en lugar de arriesgarse a «desperdiciarlos», dándoselos a un partido sin ninguna perspectiva real de victoria. Un tratado sobre este tema (Meehl, 1977) defendía, incluso, que puesto que ningún votante individual puede esperar seriamente que su opción determine el resultado de unas elecciones, el concepto de «voto desperdiciado» ni siquiera debería existir. Sin embargo, datos sustanciales y consistentes de nuestras encuestas revelan claramente que el votante español es muy sofisticado, y que está muy interesado en depositar un «voto útil» (lo opuesto a un voto desperdiciado).

Para probar adecuadamente las influencias «sicológicas» en el comportamiento electoral, obviamente se requieren datos a un nivel individual. Afortunadamente, nuestros datos de encuesta postelectorales de 1979 y 1982, combinados con otra información referente a los distintos contextos provinciales de la ley electoral, nos permite probar la presencia del voto estratégico y sofisticado. Para examinar dichos efectos contextuales, sin embargo, es necesario, primero, controlar los determinantes del voto a nivel individual. A menos que se haga así, existe un riesgo demasiado grande de que una variable relativa al tamaño del distrito electoral esté suplantando, de hecho, a factores socioestructurales, económicos o culturales que afectan las decisiones del voto. No se debería concluir precipitadamente, por ejemplo, que una correlación ecológica entre el tamaño reducido del distrito electoral y unos niveles bajos de apoyo al Partido Comunista sea producto de un deseo por parte de los simpatizantes del PCE de no desperdiciar sus votos; en lugar de esto, 
podría reflejar el hecho de que los individuos que residen en dichas provincias tienden a ser agricultores conservadores que nunca han tenido la intención de votor al Partido Comunista. Para controlar estos factores de orden individual, el análisis que sigue examina solamente el comportamiento electoral de los individuos que muestran una fuerte predisposición a apoyar a un partido determinado. Un análisis multivariado extenso de nuestros datos de la encuesta de 1979 reveló que el predictor más fuerte del voto por un partido concreto era la evaluación que hacía el entrevistado de ese partido, utilizando una escala de simpatía de 11 puntos, del 0 al 10 (véase Gunther, 1986 a) *. Para probar la hipótesis del voto desperdiciado (o, en este caso, del voto útil) sólo se examinó a los individuos que dieron un 9 o un 10 a un partido determinado en la escala de simpatía en 1979.

De acuerdo con los sesgos inherentes a la ley electoral, los entrevistados que evaluaron a los dos partidos nacionales más grandes en términos tan favorables tendieron a dar su voto a esos partidos: el 76 por 100 de los que dieron un 9 o un 10 a la UCD en la escala de simpatía votaron por ese partido; y el 62 por 100 de los entrevistados con una predisposición similar hacia el PSOE votaron por el Partido Socialista. Entre los que mostraron una predisposición favorable hacia los partidos que ocupaban el tercer y cuarto lugar nacionalmente, sin embargo, los niveles de apoyo electoral fueron sustancialmente más bajos: el 45 por 100 de los que situaron al PCE en las dos categorías superiores de la escala de simpatía votó, en realidad, a los comunistas; y solamente el 31 por 100 de los que dieron a AP un 9 o un 10 wotaron a ese partido conservador.

Esta presencia prima facie del voto sofisticado está fuertemente corroborada cuando el comportamiento electoral de estos entrevistados se desglosa provincia por provincia, según el número de diputados de cada distrito enviado a las Cortes. Los entrevistados con actitudes muy favorables hacia el tercer y cuarto partido, residentes en provincias grandes, estaban doblemente predispuestos a votar a esos partidos que los simpatizantes de los mismos que residían en provincias pequeñas. Lo que resulta más sorprendente es la aparente capacidad de los votantes españoles para determinar con bastante exactitud el umbral que separa las provincias en las que su partido preferido tenía buenas probabilidades de obtener representación parlamentaria de aquellas otras en las que sus votos se habrían desperdiciado verdaderamente. Aplicando los cálculos de D'Hont del «resto mayor» a un distrito electoral hipotético cuyos votos reflejaran exactamente los niveles de apoyo electoral recibidos por los partidos a escala nacional (véase cudro 2), el PCE, por ejemplo, habría recibido al menos un escaño en los distritos que eligen

* N. del. T.-En el artículo citado, la escala de simpatía hace referencia a líderes políticos y no a partidos. Conviene señalar, además, que, en dicho artículo, lo que aquí se traduce por «escala de simpatía» se había traducido por «termómetro de opinión» (en inglés: feeling thermometer). 
cinco o más diputados y no habría conseguido representación parlamentaria en los distritos más pequeños. Este umbral se refleja en el comportamiento electoral de los simpatizantes del PCE: entre los entrevistados que dieron al Partido Comunista un 9 o un 10 en nuestra escala de simpatía, en 1979 , el 52 por 100 de los residentes en provincias que eligen cinco o más diputados votó realmente por el PCE $(\mathrm{N}=93)$, mientras que en las provincias que sólo eligen tres o cuatro diputados $(\mathrm{N}=280)$ únicamente lo hizo el 25 por 100 ( $T a u B=0,23 ; \mathrm{P}<0,001$ ). AP no lo hizo tan bien en las elecciones de 1977 ni en las de 1979, lo que indica que su umbral representativo era más elevado. Entre los simpatizantes de Alianza Popular residentes en provincias que eligen seis o más diputados $(N=133)$, el 37 por 100 votó por este partido; pero en circunscripciones más pequeñas $(\mathrm{N}=64)$ sólo lo hizo el 19 por 100 (Tau $\mathrm{B}=0,18 ; \mathrm{P}<0,01)$. Por el contrario, la UCD - receptor natural de los votos de los simpatizantes de AP que no deseaban desperdiciar su voto- obtuvo resultados algo mejores en las provincias pequeñas que en las grandes (Tau $\mathrm{B}=0,07 ; \mathrm{P}<0,05$ ).

Un examen de los datos de nuestra encuesta de 1982 presenta incluso mayores pruebas de la existencia del voto sofisticado. $Y$, una vez más, sorprende bastante la sensibilidad de los votantes españoles hacia la estructura de la ley electoral. En esta encuesta introdujimos una forma diferente de medir la simpatía hacia los partidos políticos (preguntando a los entrevistados si se consideraban «muy cercanos», «algo cercanos», «más bien distantes» o «muy distantes» hacia los diferentes partidos políticos), que se reveló como mejor predictor del voto que la escala de simpatía. Utilizando este item de «proximidad» como un control, se observa que los efectos contextuales de la ley electoral son muy fuertes. Mayorías abrumadoras de los que se sentían próximos a uno de los dos partidos más grandes votaron por ese partido: el 84 por 100 de los que dijeron sentirse «muy cercanos» al PSOE votaron al Partido Socialista; y el 86 por 100 de los que tenían una disposición similar hacia Alianza Popular votaron por AP. De nuevo, los partidos más pequeños con bases de apoyo geográficamente dispersas recibieron niveles mucho más bajos de apoyo electoral por parte de sus bloques de simpatizantes respectivos: el 62 por 100 de los «muy cercanos» a una UCD que se desintegraba rápidamente votó a ese partido; el 56 por 100 de los que sentían gran simpatía por el Partido Comunista voto al PCE; y entre los que se sentían «muy cercanos» al partido en ciernes de Adolfo Suárez, el CDS, menos de un tercio votó realmente por este partido.

Un escrutinio más detallado del comportamiento electoral de estos simpatizantes de partidos, en conjunción con su distribución geográfica, no deja lugar a dudas sobre el hecho de que la ley electoral desanimó efectivamente a los electores, en ciertos contextos, a votar por los partidos que constituían su primera opción. Puesto que, en general, se esperaba que el CDS ńo obtuviera buenos resultados en su primera prueba electoral (una encuesta publi- 
cada sugería que recibiría solamente un 2 por 100 del voto; véase Cambio 16, 27 de septiembre de 1981,191), el umbral de la representación parlamentaria para este partido era bastante elevado, hecho, éste, que los votantes percibieron correctamente: el 48 por 100 de los «muy cercanos» al CDS residentes en provincias que elegían doce o más diputados $(\mathrm{N}=34)$ votó al partido de Suárez; pero sólo el 18 por 100 lo hizo entre los residentes en provincias más pequeñas $(N=81)(\text { Tau } B=0,31 ; \mathrm{P}<0,001)^{7}$. De forma similar, cantidades importantes de simpatizantes del Partido Comunista residentes en pequeñas provincias prefirieron no votar por su primera opción: tan sólo el 33 por 100 de los «muy cercanos» al PCE que vivían en provincias de cinco o menos diputados $(\mathrm{N}=35)$ votó por el Partido Comunista, mientras que el 61 por 100 de los residentes en provincias mayores $(N=149)$ sí le voto ( Tau $\mathrm{B}=0,22 ; \mathrm{P}<0,001$ ). $\mathrm{Y}$ en las provincias más pequeñas -que sólo eligen tres o cuatro diputados- el apoyo electoral de los que se sentían «muy cercanos» al PCE desapareció virtualmente: sólo un 6 por 100 de esos entrevistados $(\mathrm{N}=16)$ votó por el PCE, frente al 61 por 100 de los mismos en provincias mayores $(N=168$; Tau $B=0,33$; y $P<0,001)$.

El hecho de que puedan identificarse tendencias similares entre los que apoyan a los distintos partidos - con diferentes bases de apoyo socioeconómicas y demográficas y muy diferentes imágenes e ideologías - otorga credibilidad a la afirmación de que cantidades importantes de españoles depositaron un voto sofisticado o estratégico. Esta interpretación también es consistente con otros datos recogidos en nuestra encuesta postelectoral de 1982. Una abrumadora mayoría de los individuos que habían apoyado al Partido Comunista en 1979, pero que se abstuvieron o dieron su apoyo a otro partido en 1982, ofreció como primera o segunda razón para abandonar su propio partido la creencia de que «no tenía ninguna oportunidad de ganar» (véase Gunther, $1986 a$ ).

\section{La fuerza de la ley electoral española}

¿Cuál ha sido el impacto global de los efectos inmediatos de la ley electoral española en el nuevo régimen democrático originado en 1977? En un sentido, podemos concluir que su contribución ha sido inequívocamente positiva: los «correctivos» incluidos en la ley electoral, en efecto, han logrado los objetivos públicamente reconocidos de reducir la fragmentación del sistema parlamentario de partidos. Es de señalar que en ninguna de las cuatro elecciones generales que han tenido lugar desde la muerte de Franco ningún partido ha ganado una mayoría abrumadora de votos. No obstante, durante

7 La provincia de Avila, donde el estatus de «hijo favorito» de Suárez se tradujo en un apoyo considerable a su partido (no siendo, por lo tanto, castigada por la ley electoral), se ha excluido de la categoría de «provincias pequeñas». 
doce años España ha estado dirigida por gobiernos de un solo partido y no ha experimentado un nivel inaceptable de inestabilidad ministerial: a los socialistas les han apoyado mayorías «fabricadas» en el Congreso de los Diputados; y la UCD, sin haber tenido nunca un apoyo abiertamente mayoritario, se mantuvo en el poder más de cinco años como un gobierno de minoría parlamentaria, gracias al aumento de su mayoría simple de votos conseguido por la ley electoral y al voto constructivo de censura cimentado en la Constitución.

Si en España se hubiera institucionalizado una forma más pura de PR (como en Israel, Holanda o Italia), la formación de un gobierno apoyado por una mayoría parlamentaria habría sido extremadamente difícil. Este hecho habría tenido consecuencias especialmente graves para las Cortes Constituyentes de 1977-1979, y podría haber restringido enormemente la capacidad de maniobra de Adolfo Suárez en sus esfuerzos por conseguir un consenso constitucional (véanse Gunther, 1985 y 1987; Gunther y Blough, 1981; y Gunther, Sani y Shabad, 1986). En efecto, resulta incluso difícil imaginar qué tipo de coalición podría haberse formado durante ese período legislativo inicial. Si se hubiera adoptado una forma pura de PR, a la coalición más amplia posible de centro-derecha (incluyendo la UCD, AP, los catalanes y el Partido Nacionalista Vasco) todavía le habría faltado una mayoría de, aproximadamente, diez escaños. Y una reencarnación del Frente Popular (que incluyera al PSOE, al PCE, al PSP de Tierno y a Esquerra) no habría alcanzado una mayoría gobernante, faltándole más de veinte escaños. Unicamente una Grosse Koalition de la UCD y el PSOE (difícilmente imaginable en aquellos primeros días de la democracia española) podría haber asegurado una mayoría holgada en las Cortes.

Los efectos no inmediatos de la ley electoral en el sistema de partidos, sin embargo, no han sido nítidos ni unidireccionales. Los efectos mecánicos de la ley, combinados con la tendencia ampliamente conocida de los votantes españoles a depositar un voto útil y a no desperdiciar sus votos en partidos más pequeños, deberían haber simplificado drásticamente el sistema de partidos. Los líderes de los pequeños partidos con bases de apoyo geográficamente dispersas deberían haber inducido las fusiones o la formación de coaliciones electorales con otros partidos de ideología comparable. No adoptar dichas estrategias racionales maximizadoras de la representación condenaría, en principio, a la extinción a los partidos poco importantes. Y, de hecho, hemos observado algunos indicios de tendencias en esta dirección. El aumento continuado, de 1977 a 1986, del índice de proporcionalidad relativo a España indica que los votantes han aprendido progresivamente a concentrar sus apoyos a los partidos con ciertas posibilidades reales de ganar escaños en el parlamento. $\mathrm{Y}$ el número de partidos que presentó candidatos y recibió votos en elecciones nacionales disminuyó algo: de 78 en 1977 a 51 en 1979.

Pero este proceso de simplificación del sistema de partidos dista mucho 
de ser completo. El proceso de «criba» parece haberse detenido después de las primeras elecciones democráticas. En las elecciones generales de 1982 y 1986, 59 y 56 partidos, respectivamente, presentaron candidatos y recibieron votos. Las elecciones de 1986, además, pusieron de manifiesto una reducción de la proporción del voto total recibida por los dos partidos más grandes (del 74,7 por 100 en 1982 al 70,5 por 100 ), y el número de partidos con representación en el Congreso aumentó de diez a doce. Además, el registro de los partidos en el Ministerio del Interior ha continuado sin disminuciones: el 1 de enero de 1987 todavía había más de 500 partidos registrados oficialmente (véase el Anuario El País, 1987, 97-103). Aún más significativo, la fragmentación en el centro del espectro político después de las elecciones de 1982 ha impedido hasta ahora el resurgimiento de un partido o coalición con capacidad para presentar un desafío electoral creíble al PSOE de Felipe González. Globalmente, la persistencia de la fragmentación del sistema de partidos sugiere, ciertamente, que la relación entre las leyes electorales y los sistemas de partidos no es directa, automática ni determinista.

El comportamiento de los líderes de los partidos revela claramente que la evolución del sistema de partidos español no puede interpretarse simplemente como una respuesta directa a los incentivos inherentes al sistema electoral. El amplio reconocimiento de los sesgos de representación del sistema debería haber servido como un potente elemento disuasorio frente a las escisiones y a la fragmentación del sistema de partidos, así como para inducir las fusiones entre grupos de partidos pequeños. Lógicamente, esto debería haber contribuido a la estabilización y consolidación del sistema de partidos. Sin embargo, el surgimiento de partidos nuevos, las escisiones en viejos partidos y la obstinada resistencia a las fusiones o coaliciones con otros grupos ha sido un tema recurrente en la política partidista española durante la última década.

De hecho, la ley electoral desempeñó un papel paradójicamente desestabilizador en el ejemplo más dramático de este fenómeno: el colapso de la UCD en 1982. A pesar de la estructura de incentivos inherente a la ley, no se logró impedir la fragmentación del partido que había gobernado anteriormente, y una vez comenzado su proceso de desintegración, la propia ley contribuyó al declive electoral de la UCD y aceleró su caída en picado, contribuyendo a largo plazo a la fragmentación del centro político. El comportamiento irracional de las élites de los partidos en éste y episodios relacionados revela las limitaciones del papel de las leyes electorales en la determinación de los perfiles de los sistemas de partidos. 
Escisiones, coaliciones y fusiones: el papel de las élites

La simplificación del sistema de partidos requiere que los líderes respondan a los incentivos que presenta la ley electoral, evitando escisiones en los partidos existentes o formando coaliciones electorales con partidos similares o uniéndose a ellos totalmente. Esta estructura de incentivos, por otra parte, se basa estrictamente en el supuesto de que los líderes de los partidos tendrán esta clase de comportamiento para maximizar su representación parlamentaria y de que se pondrán este objetivo por encima de cualquier otro. Vamos a examinar tres grupos de decisiones tomadas por líderes de partidos españoles, durante el período 1982-1986, que fueron cruciales en este sentido. Al analizarlas, observaremos la naturaleza compleja y multidimensional de dichas opciones para comprender por qué los efectos no inmediatos de las leyes electorales en los sistemas de partidos no son directos, uniformes ni deterministas. Este análisis está basado en las simulaciones de Giacomo Sani de diferentes estrategias de coalición (extrapolando de los datos reales relevantes para las dos elecciones que estamos considerando), además de unas extensas entrevistas en profundidad que realizó el autor de este artículo a todas las élites pertinentes durante este período (véase Sani y Gunther, 1986).

\section{La unidad centrista}

La primera coalición posible a examinar es la que vincularía a la UCD con el nuevo CDS de Adolfo Suárez. Por numerosas razones, ésta habría sido una combinación plausible y potencialmente beneficiosa. Después de todo, la mayor parte de los fundadores del CDS habían sido miembros o líderes de la UCD antes del 29 de julio de 1982. Y para mantener esa «coalición» previamente a esta fecha, el único requisito indispensable era haber evitado una escisión abierta. Pero incluso después de la separación formal de Suárez de su partido anterior se realizaron serios esfuerzos para establecer una coalición electoral entre los dos partidos.

Aunque nuestra simulación sólo intentaba estimar las consecuencias de esta coalición para la representación, mediante la suma de los votos recibidos por los dos partidos en 1982 (realizando posteriormente los cálculos del «resto mayor» de D'Hont para cada distrito), es concebible que dicha combinación pudiera haber aportado mayores ventajas electorales. Los dos grupos podían haberse complementado mutuamente, como había sucedido en 1977 y 1979. Sin Suárez, la UCD fue conducida a las elecciones por un candidato (Landelino Lavilla) sin atractivo popular: en efecto, su puntuación media en la escala de simpatía de nuestra encuesta de $1982(3,3)$ fue jinferior a la de Francisco Franco! $(3,8)$. Y, sin la UCD, los esfuerzos electorales de 
Suárez sufrieron serias cortapisas en términos de infraestructura provincial y recursos financieros. De este modo, como vimos anteriormente, Suárez se convirtió en un blanco fácil de los ataques de partidos rivales basados en el «voto desperdiciado». Quizá más importante, la visibilidad que adquirió ante el electorado la traumática escisión de julio de 1982 dañó la reputación personal de los líderes de la UCD y del CDS, y desgastó la confianza de sus rcspectivos votantes. Hemos demostrado en otro lugar que la mayoría de los electores que abandonaron la UCD en 1982 citaron los continuos enfrentamientos internos y el estilo de liderazco de la élite de este partido como razones para cambiarse a otro (véase Gunther, 1986 a y 1989, de próxima aparición). De este modo, la escisión centrista tuvo un «efecto multiplicador» en la representación parlamentaria de los partidos de centro. No solamente sometió los divididos partidos a los efectos perjudiciales de la ley electoral, sino que desanimó a los antiguos votantes de UCD a apoyar a este partido o al CDS, movidos por un rechazo ante tanta discordia.

Este tipo de simulaciones, no obstante, debe interpretarse con cautela. No hay forma de predecir la reacción de los electores ante la posibilidad de votar por una lista que incluyera candidatos de ambos partidos. Contrariamente a la especulación previa, es posible argumentar que dicha lista podría haber repelido a algunos votantes. (En efecto, cuando se preguntó a nuestros entrevistados de 1982 si existía algún partido o partidos a los que nunca habrían apoyado, el 10 por 100 de los que habían votado al CDS dijeron que nunca votarían a la UCD, y el 6 por 100 de los que votaron a la UCD dijeron que nunca apoyarían al CDS.) De este modo, con simplemente añadir los votos recibidos por cada uno de estos partidos, no estamos considerando las posibles deserciones de la coalición ocurridas por aversión hacia el otro partido. Por otro lado, como se ha señalado anteriormente, los votos que podían haberse dirigido a la coalición UCD-CDS podrían haber superado el número total obtenido separadamente por cada uno de esos partidos. Nos quedamos sin saber si el balance neto de estas consideraciones rivales habría tenido una influencia positiva o negativa en el apoyo a esta coalición hipotética, limitándonos, simplemente, en nuestra simulación a sumar los dos totales de votos obtenidos.

Los resultados de la misma sugieren que dicha coalición habría modificado el voto en 14 provincias. La alianza habría conseguido un escaño en cada una de las doce provincias en las que ninguno de los dos partidos lo había obtenido en 1982, doblándose la representación del centro, en otros dos distritos, por la obtención de un escaño extra. Una candidatura combinada UCD-CDS, por tanto, podría haber ganado un total de 27 escaños (más del doble de lo que obtuvieron los dos partidos por separado en 1982 -once para la UCD y dos para el CDS-, y el triple de la delegación de AP en el parlamento anterior).

Estas ganancias netas de representación para la coalición UCD-CDS ha- 
brían tenido un impacto significativo en las futuras perspectivas del centro y en la dinámica de la competencia partidista. Primero, puesto que las hipotéticas ganancias habrían tenido lugar principalmente en provincias en las que ninguno de los dos partidos obtuvo ningún escaño, esta agrupación política de centro habría adquirido una base geográfica mucho más amplia. Segundo, las ganancias de UCD-CDS habrían sido lo suficientemente sustanciales para permitir que la coalición formara un grupo parlamentario para sobrevivir, reorganizarse e intentarlo de nuevo, quizá con mejores resultados, en futuras elecciones. Como dijo el sectetario general fundador de la UCD (quien había estimado correctamente la representación parlamentaria de una coalición UCD-CDS en aproximadamente 30 escaños), en una entrevista en 1983, «habría quedado un grupo parlamentario embrionario, con unas perspectivas de futuro mucho mejores que el desastre total ocurrido finalmente». En lugar de esto, la UCD desapareció posteriormente, y la delegación del CDS en las Cortes durante el período 1982-86 estuvo formada por Adolfo Suárez y su cuñado.

La dinámica actual de la competencia partidista podría ser diferente de haber materializado dicha coalición. Aun cuando el CDS haya sobrevivido a lo que Suárez denominó su «larga marcha a través del desierto», y aun habiendo aumentado su representación en las Cortes (19 diputados en 1986), una persistente hostilidad hacia Suárez por parte de muchos de sus antiguos colaboradores de UCD (quienes le culpan de haber contribuido a la desaparición de este partido) ha obstaculizado sus esfuerzos por construir una alternativa creíble de centro al PSOE. Conviene señalar, además, que incluso después de cuatro años de erosión del apoyo al gobierno socialista en el poder y después de considerables esfuerzos por restablecer un partido centrista viable, la delegación que representaba al centro en el parlamento, en 1986, consistía en ocho diputados menos de los que, según nuestra simulación, podría haber obtenido en 1982.

¿Por qué no respondieron estas élites partidistas a los incentivos inherentes a la ley electoral española formando una coalición? Como se revela clara y contundentemente en las entrevistas realizadas a la élite, todos los líderes pertinentes eran conscientes de esta estructura de incentivos, lo que permite descartar una posible explicación. En su lugar, las entrevistas para este estudio de caso han sugerido que había otros dos factores contribuyentes al abandono de lo que, por lo demás, podría haberse considerado un curso de acción «racional»: 1) otros objetivos políticos cobraron más importancia, en 1983, que la maximización de la representación parlamentaria; y 2) algunos actores clave calcularon erróneamente sus niveles probables de apoyo, no apreciando, por lo tanto, completamente, el impacto devastador que tendría la ley electoral.

Testimonios de diversas fuentes sugieren que Suárez abandonó el partido que había creado, principalmente, porque consideraba inaceptable la continua- 
ción del status quo. Su precio por permanecer en la UCD (como afirmaba un líder clave del partido en una entrevista) consistió en exigir que se le garantizara autoridad para «reconstruir el partido desde abajo, fundándose en el apoyo de las bases y eliminando a los líderes establecidos previamente (congelándolos, por así decirlo, por una temporada)». En una ronda de negociaciones con Landelino Lavilla y el Presidente saliente Leopoldo Calvo Sotelo, en julio de 1982, Suárez propuso a este último que renunciara a sus puestos de liderazgo tanto en el Gobierno como en el aparato del partido. Según los términos de esta propuesta, Suárez se convertiría en el presidente del partido, con pleno control sobre la elaboración de las listas electorales; Lavilla sería designado candidato a Presidente del Gobierno por la UCD; y Calvo Sotelo y otros «barones» del partido se mantendrían a un lado por un período de al menos dos años, mientras una nueva generación de líderes de UCD iban a ocupar sus lugares en el parlamento y en el Gobierno. Esta drástica cirugía era necesaria, en opinión de Suárez, para eliminar dos fuentes de inestabilidad en el seno del partido. La primera de ellas era la estructura baronial que existía de facto en el liderazgo de UCD, posibilitando que cada facción dirigente individual persiguiera «intereses $[\mathrm{y}]$ ambiciones personales de poder» de forma incontrolada. Suárez también creía que esta vaga estructura de autoridad exponía el partido a presiones excesivas de los poderes fácticos (los grandes bancos, la Iglesia y los militares) y debilitaba su capacidad para gobernar.

Sin una reestructuración radical del liderazgo del partido, Suárez y sus colaboradores concedían poco valor a una victoria electoral a corto plazo. Como dijo uno de ellos en una entrevista:

"¿Qué ganamos con tener 60, 70,80 ó 120 diputados, si continuamos como estamos abora: si elegimos a un grupo que favorece un pacto con el PSOE y rechaza la disciplina de UCD, y a otro que favorece un pacto con Fraga y rechaza la disciplina de UCD, y a otro que amenaza con irse si no le damos tres ministerios? Eso no es un partido politico. Necesitamos listas que incluyan personas dispuestas a aceptar la disciplina de partido. $Y$ si no es así, no babremos conseguido nada.»

Suárez se hizo eco de estos sentimientos en una entrevista publicada: «No tengo contianza en que, con tantos proyectos políticos personales y tanto clientelismo político, la UCD pueda tener un grupo parlamentario coherente después de las elecciones generales... ¿Qué se puede bacer con unos ministros que en cuanto salen del despacbo empiezan a conspirar contra mi, o telefonean a los periódicos para bablarles de las reuniones privadas que acabamos de tener?» (Cambio 16, 9 de agosto de 1982, 18). Resumiendo, Suárez impuso unas exigencias radicales como precio por su continuación en la UCD, en parte como reacción a los ataques personales a los que había estado sometido du- 
rante los dos años anteriores, y porque le preocupaba que, de no reformarse la estructura del partido, continuara existiendo una situación de ingobernabilidad.

No es sorprendente que sus exigencias hayan resultado inaceptables a otros líderes del partido. Como expresaba uno de los tres participantes en las negociaciones de julio, "Suárez quería que le entregáramos el partido a él, y que lo cntregáramos a un régimen dictatorial: disolviendo los organismos colegiados del partido, el ejecutivo, el Consejo Político; que le entregáramos a él plenos poderes; que él personalmente tuviera los poderes que los estatutos otorgan al Ejecutivo y al Consejo Político; y que él pudiera bacer $y$ deshacer sin tener que rendir cuentas a nadie basta las elecciones siguientes». Rechazó, por tanto, las exigencias de Suárez, clausurándose definitivamente toda posibilidad de colaboración en las elecciones de 1982. En pocas palabras, tanto Suárez como sus adversarios en el liderazco de UCD consideraron que la estructura básica del partido era más importante que las perspectivas de mejorar sus oportunidades de ganar escaños en los comicios de 1982.

Pero la incertidumbre y los desaciertos en los niveles probables de apoyo a un CDS, independiente también intervinieron en las decisiones de Suárez. Una encuesta de opinión publicada poco antes de las negociaciones SuárezCalvo Sotelo-Lavilla sugería que Suárez y los segmentos progresistas de la UCD podrían llegar a elegir 55 diputados a las Cortes de 1982 (Cambio 16, 28 de junio, 25). Dada la descomposición acelerada de la delegación parlamentaria de UCD en aquel momento, no era de todo punto imposible que cantidades sustanciales de diputados de UCD o sus dirigentes provinciales pudieran abandonar este partido para apoyar al de Suárez. La misma encuesta sugería también que dicho partido podría desempeñar un papel central en la formación de futuras coaliciones de gobierno: se esperaba que el PSOE ganara 159 escaños en un parlamento nuevo y que, por tanto, muy probablemente necesitara formar coalición. Debido a las desagradables experiencias previas de Suárez en los gobiernos de UCD, una coalición de gobierno PSOE-CDS podría haberse presentado como una alternativa atractiva.

Pero Suárez se equivocó respecto a dos componentes importantes de esta estrategia. Primero, no tuvo en consideración la lealtad a la UCD que estaba surgiendo entre varios aliados potencialmente importantes. Muy pocos miembros de la élite de UCD siguieron a Suárez al CDS. Incluso personas que habían sido sus aliados ideológicos, amigos personales y colaboradores cercanos rehusaron unirse al nuevo partido disidente. La desgana imperante en segmentos progresistas de la UCD a abandonar su partido fue resumida correctamente por un anterior secretario general del mismo en el momento de tomarse estas decisiones: «Si bemos viajado por toda España durante estos años trabajando para la UCD, defendiendo al partido y pidiendo votos, ¿cómo vamos abora a decir a esa misma gente que no ba servido para nada, y que 
deberían votar a un partido distinto?» Segundo (y quizá como resultado de la escasez de deserciones de personas destacadas en la UCD), Suárez sobreestimó gravemente las perspectivas electorales de un partido centrista fuera de la UCD. Como consecuencia de estos desaciertos, también infraestimó los rasgos inherentes a una salida repentina de la UCD.

Menos de un mes después de que Calvo Sotelo rechazara sus exigencias, Suárez anunció la formación de su propio partido, el Centro Democrático y Social. Y el resto, como suele decirse, es historia.

\section{La Gran Derecha}

La segunda coalición hipotética a explorar es la que se conoce en España como una alianza de la Gran Derecha, que uniría las fuerzas de UCD con las de Alianza Popular. Esta combinación se habría ajustado a los viejos deseos de Manuel Fraga de combinar los «sectores centristas y de centroderecha, y de establecer las bases de un partido futuro como los Conservadores ingleses y el partido Republicano americano». En efecto, la creación de un único partido grande que atrajera el apoyo de todos los votantes situados a la derecha del centro fue el objetivo original de Fraga al fundar Alianza Popular en 1976 (véase Gunther, Sani y Shabad, 1986, cap. 3). Al estallar los conflictos internos que acosaron a la UCD durante los dos años y medio que precedieron a las elecciones de 1982, a Fraga se le presentó la oportunidad de reestructurar el sistema de partidos a expensas del heterogéneo partido de centro. Como explicaba en 1981 un alto dirigente de AP, en una entrevista: "Grupos de ciudadanos están trabajando en importantes sectores de la UCD que se ban dado cuenta de que no pueden estar en un mismo partido los que se pronuncian a favor del divorcio y los que se oponen, o los que están a favor de una política fiscal colectivista y los que están en contra. Estamos ecbando una nueva ojeada a esos grupos conservadores y democristianos.» A lo largo del año que precedió a las elecciones de 1982, los líderes de AP intensificaron sus esfuerzos por fomentar deserciones individuales de políticos de UCD (como fue el caso del portavoz parlamentario del partido centrista, Miguel Herrero de Miñón) o claras escisiones (como la que culminó en la creación del democristiano Partido Demócrata Popular, PDP) que podrían facilitar una coalición más amplia de fuerzas de centro-derecha. Y, precisamente la víspera de esas elecciones, comenzaban las primeras discusiones relativas a formalizar una coalición entre AP y los restos de UCD.

Esta estrategia era compatible con las preferencias y cálculos políticos de algunos dirigentes de UCD, ajustándose también a sus percepciones del impacto de la ley electoral española en el sistema de partidos. Como afirmaba 
- algo imprecisamente- el futuro fundador del PDP en una entrevista en 1981 (cuando todavía era un diputado de UCD):

«En España tenemos una ley electoral poco común. Hay 50 distritos provinciales, en su mayoría distritos rurales pequeños, que están sobrerepresentados por tres a uno: un voto en Segovia o en Avila vale por tres en Madrid. En estos distritos, Alianza Popular, por lo general, tiene un apoyo considerable, pero no suficiente, para elegir un diputado, porque son distritos que eligen tres o cuatro diputados. Si se analizaran los resultados electorales y se sumaran los votos de AP a los nuestros, en tres cuartas partes de las provincias elegiriamos un diputado extra a expensas de la izquierda. Los beneficios de formar una coalición electoral con Alianza Popular son obvios.»

En las semanas precedentes a la presentación de las listas para las elecciones de 1982 se habló de una posible coalición entre la UCD y AP (Manuel Fraga argumentaba que atraería a una «mayoría natural» de españoles). Ciertos líderes del sector conservador democristiano de UCD y algunos otros dirigentes conservadores del partido habían favorecido durante algún tiempo dicha alianza. Algunos, de hecho, ya habían dejado el partido para entrar en AP directamente (por ejemplo, Herrero), o para formar una coalición con AP dentro del nuevo PDP de Oscar Alzaga. Otros que permanecieron en la UCD (como José Luis Alvarez) presionaron para formar una alianza con AP antes de las elecciones del 28 de octubre. El debate sobre esta propuesta de alianza culminó en una reunión de los líderes del partido en Madrid. El 7 de septiembre la UCD rechazó esas propuestas e hizo una «proclamación pública solemne» de su intención de mantenerse independiente. Algunos dirigentes de UCD (como José Luis Alvarez) dimitieron en señal de protesta, y se unieron a la coalición AP-PDP.

Nuestra simulación de esta alianza electoral sugiere que una coalición UCD-AP-PDP habría ganado 14 escaños más de los que obtuvieron realmente estos partidos presentando listas separadas de candidatos. $Y$ aunque este tipo de simulaciones no están exentas de las habituales reservas, sus resultados indican que las perspectivas de supervivencia de la UCD podrían haber mejorado considerablemente si se hubiera formado la coalición. Al no haber sido así, sin embargo, los efectos mecánicos de la ley electoral redujeron sustancialmente la delegación de ese partido en las Cortes, y las fórmulas de financiación de las campañas, también sesgadas, lo condujeron a la quiebra.

¿Cómo se explica el rechazo de la UCD a formar dicha coalición? Las entrevistas a los protagonistas de este drama y sus declaraciones públicas sugieren que detrás de su rechazo a adoptar lo que la ley electoral habría definido como un comportamiento racional encontramos cinco factores. El primero es que esa coalición habría reptesentado el abandono de una de las 
creencias y compromisos fundamentales de la UCD: que en España es necesario un partido centrista fuerte e independinete, porque un sistema de partidos bipolar provocaría discordias y, potencialmente, la desestabilización del régimen. Segundo, la hostilidad y desconfianza personal hacia Manuel Fraga y su partido conservador estaban muy extendidas. Tercero, dicha coalición habría chocado con la heterogeneidad ideológica de la élite de la UCD y con las inclinaciones progresistas de muchos de sus líderes. (Estos dos últimos puntos se ponen de manifiesto en una entrevista de 1983 a un antiguo secretario general de la UCD, quien, al ser consultado sobre la conveniencia de coaligarse, respondía: «;Yo ni siquiera votaría a Fraga! Le tengo mucbo más miedo a Fraga que a Felipe. Mucho nás. Sé que Felipe es un demócrata. De Fraga, no estoy tan seguro. No me siento nada identificado con la derecha española, porque no es una derecha moderna».)

Un cuarto factor se basó en una consideración táctica: en septiembre de 1982 las encuestas de opinión habían indicado que la UCD tendría que ser un socio de segunda fila en esta coalición, y esto resultaba inaceptable para muchos dirigentes del partido. Otro antiguo secretario general de UCD señaló que «la idea de una coalición babía partido de AP. Alianza Popular ocupa el asiento del conductor, con el convencimiento de que debería ser el protagonista y director principal de dicba coalición. Estariamos bajo el liderazgo del señor Fraga. ¡No! Representaría la desaparición de la UCD y la desaparición de un espacio político que el CDS no podría cubrir por sí mismo».

Por último, la incertidumbre respecto a los niveles reales de apoyo de cada uno de los socios de la futura coalición mermó el atractivo de esta propuesta. Muchos líderes de UCD creían que, con Fraga, AP nunca superaría un techo electoral en torno al 20 por 100 del voto. Esto, sumado a que los datos de encuesta indicaban que un segmento sustancial del electorado no se había decidido todavía un mes antes de las elecciones, llevó a algunos a concluir que las ventajas electorales de una alianza con AP no serían tan favorables y que las perspectivas de una UCD sin coaligarse con nadie podrían no ser tan malas como, al final, se demostraron.

Una vez más, los líderes del partido no actuaron de forma coherente con los incentivos que ofrecía la ley electoral, debido a la incertidumbre sobre sus niveles probables de apoyo, y a que consideraron prioritarios otros intereses y objetivos políticos ajenos a la obtención de una ventaja electoral a corto plazo.

\section{La fragmentación de la derecha}

El tercer estudio de caso es muy diferente de los dos que le han precedido: consiste en una exploración de las ventajas y desventajas de una coalición electoral que, de hecho, se había formado realmente antes de las 
elecciones de 1982. La historia de la alianza entre el democristiano PDP (formado en 1982 como resultado de una escisión en la UCD), Alianza Popular y dos grupos liberales minúsculos (la Unión Liberal, en 1982, y el Partido Liberal, en 1986) ofrece mayores pruebas de la complejidad de los compromisos que hay que tener en cuenta al contemplar la formación de coaliciones electorales. También indica por qué los líderes de los partidos deberían ser extremadamente prudentes a la hora de entrar en ese tipo de acuerdos.

Los dirigentes de AP y del PDP dieron tres razones cuando se les pidió que explicaran por qué habían formado Coalición Popular en 1982. La primera es que, habiendo anticipado los efectos mecánicos y sicológicos de la ley electoral, esperaban que los votos obtenidos por el recientemente creado PDP fueran suficientes para aumentar sustancialmente la representación de los conservadores en las Cortes. En este sentido, la coalición AP-PDP-PL era una versión en cierta forma frustrada de la estrategia de la Gran Derecha, preconizada por Manuel Fraga durante varios años. Como es habitual cuando se llega a este tipo de acuerdos, los niveles probables de apoyo electoral de cada miembro de la futura coalición estuvieron rodeados de gran incertidumbre. El PDP (en su esfuerzo por negociar autónomamente numerosas posiciones favorables en las listas electorales) sobreestimó decididamente su apoyo electoral y, en cierta medida, logró convencer a los líderes de AP de que podría desempeñar un papel decisivo en aumentar la presencia parlamentaria de la derecha.

Una segunda razón ofrecida es que los dos grupos de élites creyeron que sus electorados potenciales eran complementarios, aunque distintos, y que esto podría incrementar aún más su electorado combinado. Creyeron, por ejemplo, que los democristianos centristas y de centro-derecha que no se sentían especialmente atraídos por AP podrían ser persuadidos de votar por una coalición que incluyera un partido como el PDP. Al mismo tiempo, argumentaban que individuos que es posible que nunca llegaran a arriesgarse a «desperdiciar» sus votos en un partido pequeño como el PDP, podrían apoyar una coalición más amplia de centro-derecha.

La tercera razón fundamental fue principalmente histórica, centrándose no tanto en las posibles contribuciones de! PDP a unas futuras elecciones, como en lo decisiva que había sido su creación en la reestructuración del sistema de partidos en 1982. Como afirmaba un líder provincial de AP en una entrevista, el PDP no era tanto un partido electoral como «una operación diseñada para destruir a la UCD. Así es como nació el PDP; con claras intenciones de aliarse con AP. Nació con la ayuda de AP para acabar de una vez con la UCD. Fue concebido como el lugar de reunión de los desengañados con la UCD». En este sentido, la alianza de AP con el PDP fue claramente exitosa. Hemos demostrado en otras ocasiones (véanse Sani, 1986, y Gunther, 1986 a) que las dramáticas ganancias electorales de AP se hicieron 
a costa de la UCD, y que el factor principal del colapso electoral de la UCD fue la indecorosa descomposición de su élite. Pero, en otras dimensiones, también podría considerarse que la coalición ha tenido consecuencias decididamente perjudiciales para Alianza Popular.

En primer lugar, el efecto mecánico de la ley electoral produjo un aumento insignificante en la representación parlamentaria de la derecha como producto de esta coalición. Simulamos las elecciones de 1982 como si AP, el PDP y los liberales hubieran presentado listas separadas de candidatos, utilizando para la estimación del voto correspondiente a cada partido los votos que realmente había recibido en las elecciones municipales de 1987, cuando, de hecho, sí se habían presentado en listas separadas. (Esta simulación requiere advertencias adicionales a las que hicimos anteriormente: no podemos estar seguros del grado de coincidencia entre el apoyo electoral de cada partido y los niveles reales de apoyo recibidos cuatro años y medio más tarde, aunque los datos de una encuesta de opinión sugieren que, durante este período, no se produjo ningún cambio significativo en el apoyo a estos partidos.) Los niveles reales de apoyo electoral obtenidos por el PDP y el PL en las elecciones municipales de 1987 fueron extraordinariamente bajos: a nivel nacional, el PDP sólo recibió unos 150.000 votos, y el Partido Liberal menos de $11.000^{8}$. En contraste, Coalición Popular recibió más de 5,2 millones de votos en 1982. Así, pues, nuestra simulación de las elecciones de 1982 -en que los tres partidos se presentaban por separado- revela que el PDP tuvo una contribución neta de dos escaños a la delegación parlamentaria conservadora (de no ser así, el CDS y el PSOE habrían ganado un escaño cada uno), y que el PDP sólo habría elegido, por un escasísimo margen, a un diputado. El impacto, por tanto, en el equilibrio de fuerzas partidistas en las Cortes habría sido mínimo.

Desde la perspectiva de AP, la formación de Coalición Popular en realidad redujo sustancialmente la representación de ese partido en las Cortes. Concediendo credibilidad a nuestra simulación, si AP se hubiera presentado por separado en 1982, habría obtenido 103 diputados. Sin embargo, en el Congreso de los Diputados solamente se concedieron escaños a 83 candidatos de AP. Esto se debe a que los socios de AP en la coalición, y especialmente el PDP y los liberales, fueron objeto de un tratamiento generoso por parte de Fraga, quien los situó en posiciones favorables en las listas electorales. A pesar de su pobre contribución electoral a Coalición Popular (nuestra es-

${ }^{8}$ Fuente: Ministerio del Interior, Elecciones Municipales 1987: Recuento Provisional. El PDP recibió solamente 117.000 votos en las provincias en que se presentó separadamente con su propia lista de candidatos. En Galicia formó parte de Coalición Galega, por lo que se hace necesario interpolar la estimación. Hemos estimado muy generosamente (en torno a 33.000) la cuota correspondiente al PDP en el voto obtenido por CG, produciendo un total nacional de 150.000 votos. Esta cifra se aproxima mucho al total de los votos obtenidos por el PDP (170.866) en las elecciones al Parlamento Europeo de 1987 (para las que no contamos con datos provinciales). 
timación de la parte correspondiente al PDP en el voto de CP fue sólo de un 3 por 100 del total, aproximadamente), a los democristianos de Oscar Alzaga se les adjudicaron 16 escaños en el Congreso de los Diputados en 1982 , lo que equivale, aproximadamente, a un 15 por 100 del total de la delegación de CP. Y a los liberales asociados a la prácticamente inexistente Unión Liberal, se les concedió media docena de escaños. En las elecciones generales de 1986, el PDP y los liberales obtuvieron incluso mejores resultados. A los democristianos de Alzaga se les dio el 21 por 100 del total de puestos en la lista electoral a escala nacional (comparado con un 11,5 por 100 para el Partido Liberal y un 67,5 por 100 para AP), y obtuvieron 22 escaños en el Congreso, o el 21 por 100 del grupo parlamentario de CP. Más sorprendente todavía, el Partido Liberal (que, recordemos, ¡sólo recibió 11.000 votos a escala nacional en las elecciones municipales del año siguiente!) obtuvo 12 diputados, o el 11 por 100 del total de escaños de Coalición Popular. Como resultado, en lugar de una delegación parlamentaria de más de 100 -que habría obtenido Alianza Popular si hubiera presentado una sola lista de candidatos correspondiente a su partido--, la representación de AP contó solamente con 71 diputados. La generosidad de Fraga hacia sus socios de coalición fue resentida amargamente por los permanentes de AP, y dio lugar a un conflicto considerable dentro del partido en algunas agrupaciones regionales.

A largo plazo, la formación de Coalición Popular puede que incluso haya tenido consecuencias aún más negativas, cuando no desastrosas, fruto de las rencorosas disputas surgidas como resultado de las elecciones de 1986. Desde un principio había existido preocupación en la élite de AP sobre las consecuencias de una relación estrecha con el PDP. Los papeles prominentes desempeñados por el secretario general y por el presidente del PDP (Alzaga y Alvarez) en la destrucción de la UCD motivaron una desconfianza extrema hacia ellos en algunos líderes de AP, hasta el punto de oponerse a cualquier tipo de fusión entre los dos partidos. Cuando en una entrevista, en 1983, se le preguntó al secretario general de Alianza Popular por qué no había habido una fusión formal entre AP y el PDP, su respuesta fue: «Conozco demasiado bien la bistoria de la UCD para aceptarlos dentro de Alianza.» Después, pasó a describir a Coalición Popular como una flota naval, donde AP representaría el buque insignia: "Primero, está el portaaviones (AP). Después, bay dos o tres destructores que están muy bien donde están. Si los destructores quieren formar parte de la flota, estupendo. iPero no van a intervenir en nuestros asuntos internos!» Otro miembro autorizado de AP añadía: «Están aliados con nosotros, pero muy oportunistamente. Sólo en la medida en que nos necesitan.»

Los acontecimientos que tuvieron lugar en los años siguientes sugieren que estas sospechas estaban bien fundadas. Durante la primera conferencia de prensa después de las elecciones de 1986 (en las que Coalición Popular 
perdió dos escaños, principalmente como resultado de la deserción de dos pequeños partidos regionales de la coalición), el líder del PDP, Alzaga, lanzó un ataque contra Manuel Fraga, basándose en la necesidad de que CP estuviera dirigida por una figura política nueva. De no ser así, argumentaba, nunca ganaría una elección. A los pocos meses, la coalición se deshizo y surgieron las luchas por el liderazgo en el seno de los partidos que la componían. $Y$, en menos de un año, tanto Fraga como Alzaga se vieron forzados a dimitir como líderes de los partidos que habían fundado. En Alianza Popular se desató una crisis de la que este partido aún no se ha recuperado completamente. Así, pues, una de las importantes contribuciones positivas de Manuel Fraga y sus colaboradores después de la escisión de 1978 —un liderazgo unificado y estable - quedó destruida por las asperezas creadas como consecuencia de una ligera decepción electoral para Coalición Popular. La disolución de la delegación de Coalición Popular en el Congreso de los Diputados (con la entrada del PDP y del PL en el Grupo Mixto) ha resultado no sólo en un aumento de la fragmentación partidista en el parlamento (lo que se pretendía paliar explícitamente con la ley electoral), sino también en un agravamiento del desequilibrio de la fuerza de los socialistas y el mayor partido de la oposición.

\section{CONCLUSION}

Estas simulaciones y exploraciones de posibles estrategias para la formación de coaliciones al nivel de las élites revelan que la ley electoral española (y las leyes clectorales en general) implican de una forma compleja y multifacética a la dinámica de la competencia partidista. Es cierto que algunos aspectos de la influencia de las leyes electorales son simples y directos: la manera en que la ley traduce votos en escaños parlamentarios es sencilla y mecánica; y el voto sofisticado o estratégico de los españoles se ha extendido tanto y es tan predecible que los llamamientos al voto útil se han incorporado de forma reguiar a las estrategias de las campañas en los grandes partidos desde las elecciones de 1979 (véase Gunther, Sani y Shabad, 1986, cap. 8). Pero los efectos no inmediatos o las consecuencias políticas a largo plazo de las leyes clectorales encierran interacciones complejas en diversos planos dentro del sistema poíítico.

Para evaluar correctamente el papel de las leyes electorales en la configuración de la competencia partidista y la formación de coaliciones, es importante comenzar con la simple noción de que este mecanismo crea una estructura predecible de ventajas y desventajas para los partidos políticos. Si no hay alteraciones circunstanciales, el comportamiento de los líderes de los partidos, funcionando como actores racionales que buscan la maximización de sus ganancias electorales, debería ser uniforme y predecible. Pero, puesto que las 
circunstancias sí se modifican, el análisis precedente sugiere que debemos alterar nuestra comprensión de los efectos no inmediatos de las leyes electorales en los sistemas de partidos de la forma siguiente:

1. Las leyes electorales constituyen «sólo uno de los elementos causales que determinan la estructura de los sistemas de partidos» (Duverger, 1986, 71).

2. La mejor forma de considerar el impacto no inmediato o a largo plazo de las leyes electorales en los sistemas de partidos es a través de la mediación ejercida por el comportamiento de los líderes de los partidos en ese impacto, comprendiendo aspectos tales como la formación de coaliciones electorales, las fusiones con antiguos rivales y las escisiones en el seno del propio partido.

3. Las leyes electorales influyen el comportamiento de las élites en estos ámbitos a base de presentar a los líderes una estructura de incentivos que incluye recompensas (como aumentos de la representación parlamentaria, y compensación monetaria de fondos públicos para campañas electorales) y castigos (como la infrarrepresentación o una franca negación de la representación parlamentaria, e incluso la quiebra).

4. El impacto de las leyes electorales en estos aspectos del comportamiento de las élites sería directo y determinista sólo en el caso de que se cumplieran las siguientes condiciones:

a) que las élites tengan pleno conocimiento de los incentivos inherentes a la ley electoral;

b) que tengan un conocimiento razonablemente adecuado de los niveles y distribución geográfica de sus propias bases de apoyo electoral y de los de sus futuros socios de coalición; y

c) que sitúen por encima de cualquier otro objetivo político el de maximizar la representación parlamentaria de sus partidos a corto plazo.

Un examen del comportamiento de las élites en España a comienzos de la década de 1980 ha revelado varios casos de incumplimiento de una o más de estas condiciones. Primero, si bien es cierto que casi todos los líderes de los partidos tenían pleno conocimiento de los sesgos de representación inherentes a la ley electoral española, algunos actores clave o tenían información incorrecta sobre su apoyo electoral probable o equivocaron intencionadamente sus posibilidades de atraerse al electorado en el proceso de negociar con sus socios potenciales de coalición. Esto deformó seriamente las decisiones sobre la formación de coaliciones electorales y produjo resultados «irracionales», si consideramos la maximización de la representación parlamentaria como un objetivo racional. 
Más importante, un número significativo de élites clave desafió la primacía de este objetivo y situó otros intereses por encima de la maximización a corto plazo de la representación parlamentaria. Entre esos otros intereses contaron las animosidades personales, el deseo de respetar las tradiciones de sus partidos respectivos y la integridad de la institución del partido, la idea de una incompatibilidad ideológica o programática con los socios potenciales de coalición, una preocupación por la forma en que ciertas configuraciones de sistemas de partidos podrían amenazar la estabilidad del régimen democrático, y el deseo de evitar una repetición de los errores del pasado.

Como consecuencia de la incertidumbre, de los errores de cálculo o de un mayor interés por cuestiones ajenas a la maximización de la representación parlamentaria a corto plazo, estas élites tuvieron un comportamiento que se alejó sustancialmente de lo que, en términos de la ley electoral, se habría definido como racional. Así, pues, incluso aunque el marco general del sistema de partidos se amolda claramente a los sesgos del sistema electoral, algunos de sus rasgos son inexplicables de otra forma. Además, ciertas desviaciones de los supuestos antes mencionados proporcionan alguna idea de por qué una ley electoral diseñada para facilitar la simplificación y estabilidad del sistema de partidos contribuyó, paradójicamente, a una crisis electoral tumultuosa y desestabilizadora en 1982.

El nivel de apoyo que es probable que reciba cada partido individual es siempre incierto hasta el momento en que se depositan los votos. Aunque la publicación de datos de encuesta ha reducido sustancialmente esta incertidumbre en años recientes, aún puede ser considerable en determinadas circunstancias. En el análisis presentado anteriormente, hemos visto que los líderes del PDP manipularon hábilmente la incertidumbre en torno al tamaño de su electorado potencial, incorporaron argumentos vinculando este nivel de apoyo a los conocidos sesgos de la ley electoral, y lograron conseguir una cuota de la delegación parlamentaria de Coalición Popular mucho mayor de lo que habría sido posible de otra forma. La simulación presentada anteriormente refuerza la postura de algunos militantes de AP de que Coalición Popular no defendió adecuadamente los intereses de su partido. Esto es así en lo que respecta a los intereses del partido a corto plazo (por asignársele a $\mathrm{AP}$ un número de escaños en las Cortes bastante más reducido de lo que hubiera conseguido por su cuenta) y, especialmente, a largo plazo (por exponer la élite previamente estable de AP a los mismos tipos de desórdenes organizativos que habían destruido a la UCD). Resumiendo, la incertidumbre, combinada con el conocimiento de los sesgos de representación de la ley electoral, condujo a AP a un comportamiento no inspirado en el cálculo racional de sus intereses partidistas. La incertidumbre también contribuyó al inicial desastre electoral experimentado por Adolfo Suárez y su CDS. Valorando en exceso su propio atractivo personal ante el electorado y su habilidad para fomentar nuevas deserciones de líderes de 
la UCD, Suárez y su partido se encontraron solos en las elecciones de 1982, y quedaron casi eliminados como una fuerza política viable.

Otras partes del análisis aquí expuesto sugieren que la maximización de los votos a corto plazo puede pesar menos que consideraciones de otra índole, conducentes a que los líderes del partido se comporten, aparentemente, de forma «irracional» (como puede ser un comportamiento incoherente con la estructura de premios y castigos inherente a la ley electoral). Nuestras simulaciones indicaban claramente que los partidos de centro se habrian beneficiado (y que la UCD, en concreto, podría haber sobrevivido a las elecciones de 1982) si hubieran evitado las escisiones, formado alianzas electorales o fomentado las fusiones. En lugar de estas alternativas, su actuación fue contraria a la lógica inherente a la ley electoral: y, una vez divididos, cayeron. ¿Por qué? Diversas razones aducidas en las entrevistas a los líderes sugieren que otro tipo de reflexiones suplantaron los simples cálculos de una ventaja electoral a corto plazo. Considerando, primero, cualquier combinación posible, las animosidades personales impidieron las alianzas: su origen hay que buscarlo en profundas sospechas alimentadas por los años (la hostilidad, por ejemplo, de gran parte de la élite de UCD hacia cualquier alianza posible con Fraga), o en cicatrices de batallas recientes, todavía demasiado cercanas para haber curado (por ejemplo, entre Suárez y varios líderes de la UCD). Un segundo bloque de consideraciones, que también impidió una coalición AP-UCD, se centraba en la compatibilidad ideológica y en las persistentes sospechas sobre el compromiso de AP con la democracia. Un tercer factor, que parece haber sido decisivo en impedir que la UCD y el CDS restablecieran una relación de colaboración, tiene que ver con modelos de organización partidista y el deseo general de evitar una repetición de los errores del pasado: Suárez se negó a permanecer en un partido en el que los influyentes «barones» podían retener una autonomía considerable y donde la disciplina de partido era débil, y Calvo Sotelo se negó a devolver el control del partido a un individuo que temía que fuera potencialmente dictatorial. Todas estas reflexiones de la élite chocan con la lógica inherente a los sesgos de representación de la ley electoral.

Estos descubrimientos conducen inexorablemente a otro conjunto de temas — referentes a la institucionalización de un partido político nuevo- que no podemos explorar en este trabajo (véanse Gunther, $1986 b$, y otro estudio de próxima aparición). Los incentivos inherentes a los sistemas electorales generan ventajas fundamentalmente al nivel del partido como institución. En muchos sentidos, esto presupone que los líderes individuales en esos partidos coordinarán sus acciones para maximizar los beneficios del partido globalmente considerado, lo que, a su vez, puede requerir que, ocasionalmente, sacrifiquen sus propios intereses individuales o de facciones. En ausencia de un extenso compromiso con el partido en abstracto, esto puede ser una tarea difícil, especialmente cuando cuestiones tales como la gobernabilidad y dis- 
ciplina interna del partido son todavía problemáticas. Por esta razón, la estructura de incentivos presentada a las élites de los partidos políticos españoles de nueva creación puede haber sido menos convincente que la que se presenta a partidos más completamente institucionalizados. De lo que se deduce que el grado de institucionalización de los partidos debería considerarse como otro conjunto más de factores que intervienen entre las leyes electorales y la estructura de los sistemas de partidos. Y en la medida en que el análisis del impacto no inmediato de las leyes electorales en los sistemas de partidos se realice al elevado nivel de abstracción que caracteriza la literatura existente sobre el tema, no podrán evaluarse adecuadamente los papeles desempeñados por estos factores mediadores.

\section{(Traducido por Natalia García-Pardo.)}

\section{REFERENCIAS}

Bensel, Richard, y Sanders, Elizabeth (1979): «The Effects of Electoral Rules on Voting Behavior: The Electoral College and Shift Voting», Public Choice, 34: 69-85.

CaIN, Bruce (1978): «Strategic Voting in Britain», American Journal of Political Science, 22: 639-655.

Del Castillo, Pilar (1986): «La financiación de las elecciones legislativas de 1982», en Crisis y cambio: Electores y Partidos en la España de los años ocbenta, eds. Juan J. Linz y José R. Montero, Madrid, Centro de Estudios Constitucionales, pp. 257-288.

Downs, Anthony (1957): An Economic Theory of Democracy, Nueva York, Harper.

Duverger, Maurice (1954): Political Parties: Their Organization and Activity in the Mo. dern State, Nueva York, John Wiley \& Sons.

Fisher, Stephen L. (1973): "The Wasted Vote Thesis: West German Evidence», Comparative Politics, 5: 293-299.

Grumm, John G. (1958): «Theories of Electoral Systems», Midwest Journal of Political Science, 2: 357-376.

Gunther, Richard (1985): «Constitutional Change in Contemporary Spain», en The Politics of Constitutional Cbange in Industrial Nations: Redesigning the State, eds. Keith G. Banting y Richard Simeon, Londres, MacMillan.

- (1986 a): «El realineamiento del sistema de partidos de 1982», en Crisis y Cambio, eds. Linz y Montero, pp. 27-70. Una versión ampliada y sustancialmente revisada de ese análisis se publicará con el título «The Electoral Earthquake of 1982», en Richard Gunther, Goldie Shabad, Juan J. Linz, José R. Montero, Hans-Jürgen Puhle y Giacomo Sani, Electoral Change and Democratic Consolidation in Spain, de próxima aparición.

- (1986 b): «El colapso de UCD», en Crisis y Cambio, eds. Linz y Montero, pp. 433-492. Una versión sustanlialmente revisada de este análisis se publicará con el título «A Crisis of Institutionalization: The Collapse of the UCD», en Electoral Change, Gunther y Shabad $t$ t al., de próxima aparición.

- (1987): «Democratization and Party Building: Contradictions and Conflicts Facing Party Elites in the Spanish Transition to Denocracy", en Spain in the 1980s, eds. Robert P. Clarke y Michael H. Haltzel, Cambridge (Mass.), Ballinger, pp. 35-66.

Gunther, Richard, y Blough, Roger A. (1981): «Religious Conflict and Consensus in Spain: A Tale of Two Constitutions», World Affairs, 143: 366-412.

Gunther, Richard; SanI, Giacomo, y SHabad, Goldie (1986): Spain after Franco: The Making of a Competitive Party System, Berkeley, University of California Press. 
Meenl, Paul (1977): "The Selfish Voter Paradox and the Thrown-Away Vote Argument», American Political Science Review, 71: 11-30.

Ministerio Del InTERIOR, Secretaría General Técnica (1979): Legislación Electoral Española, Madrid.

RAE, Douglas W. (1971) (ed. revisada): The Political Consequences of Electoral Laws, New Haven, Yale University Press.

Riker, William H. (1986): «Duverger's Law Revisited», en Electoral Laws and their Political Consequences, eds. Bernard Grofman y Arend Lijphart, Nueva York, Agathon Press, pp. $19-42$.

Rose, Richard (1984): «Electoral Systems: A Question of Degree or of Principle?», en Choosing an Electoral System: Issues and Altcrnatives, eds. Arend Lijphart y Bernard Grofman, Nueva York, Praeger.

SANI, Giacomo (1986): «Los desplazamientos del electorado: Anatomía del cambio», en Crisis y Cambio, eds. Linz y Montero, pp. 1-26.

SANi, Giacomo, y Gunther, Richard (1986): "¿Qué hubiera pasado si...? El impacto de la normativa electoral», en Crisis y Cambio, eds. Linz y Montero, pp. 125-154.

SARTORI, Giovanni (1984): «The Influence of Electoral Systems: Faulty Laws or Faulty Method?», en Electoral Laws and Tbeir Political Consequences, eds. Lijphart y Grofman, pp. 43-68.

Shively, W. Phillips (1970): «The Elusive "Psychological Factor"», Comparative Politics, 3: $115-125$.

Spafford, Duff (1972): «Electoral Systems and Volter's Behavior», Comparative Politics. 